\title{
An Asymmetric Job Auction Model ${ }^{\times}$
}

\author{
Xiaoting Wanga* \\ a Department of Economics, Acadia University, Wolfville, Nova Scotia, B4P 2R6, Canada \\ *Corresponding author's email address: xiaoting.wang@acadiau.ca
}

\section{A R T I C LE IN F O}

Received: 19-08-2015

Accepted: 22-09-2015

Available online: 23-09-2015

Keywords:

Heterogeneity;

Job auction;

Steady state equilibrium.

JEL Classification:

D83, J64, E24.

(C) 2015 The Authors. This is an open access article under the terms of the Creative Commons Attribution License 4.0, which allows use, distribution and reproduction in any medium, provided the original work is properly cited.

\begin{abstract}
A B S T R A C T
In this paper we investigate a labor market with search frictions. Workers with heterogeneous productivity apply to different types of job vacancies by bidding the optimal profits that they can offer the firms. In the steady state equilibrium, the most capable workers separate themselves by only bidding at jobs requiring high skills, while applicants in the middle of the productivity distribution pool with the low-productivity workers and apply for jobs requiring low skills.
\end{abstract}

DOI: $10.18533 /$ jefs.v3i05.167

\subsection{Introduction}

Labor market has been a very active research subject in economics during the past two decades. Researchers have devoted tremendous effort characterizing and modeling how firms and job seekers interact with each other in labor market. In directed search models search frictions arise because workers cannot coordinate their job search strategies. To increase the chance of attracting qualified workers firms often compete by publicly posting contracts (Burdett and Mortensen, 1998; Acemoglu and Shimer, 1999a). As workers randomly search among employers, an offer is assumed to be the realization of a random draw form the distribution of wage offers across employers. In equilibrium better firms commit to offering higher wages (Moen, 1997) or reward worker skills in different ways (Shi, 2001; Shimer, 2005). This yields constrained efficient outcomes (Hosios, 1990; Acemoglu and Shimer, 1999b; Mortensen and Wright, 2002; Eeckhout and Kircher, 2010). ${ }^{1}$

A relatively new strand of research on labor market is to model job search as an auction mechanism. Shimer (1999) is among the very first who propose job auctions as a theory of wage determination in frictional labor markets. Workers apply at job openings by bidding in auctions, and firms hire the applicant offering it the most profit. In equilibrium, the symmetric bidding function is strictly increasing in workers' productivity. Firms always hire the most productive applicant, but the threat of competition from less productive workers holds down the winner's wage demand. The equilibrium of the job auction model is always efficient, in contrast to the standard search models.

\footnotetext{
${ }^{x}$ Financial support from the National Natural Science Foundation of China (\#71101024) is acknowledged.

${ }^{1}$ See Rogerson et al. (2005) for a survey of search-theoretic models of the labor market.
} 
Standard search and matching models, such as Pissarides (1990) and Blanchard and Diamond (1994), usually model wage determination as a Nash bargaining process. They assume that the bargaining is between the employed worker and the firm, which contrasts with the assumption in Shimer (1999) that unemployed applicants and vacant firms bargain over wages. This modification in assumption ensures that the equilibrium of the job auction model is always efficient, while the equilibrium of the Nash bargaining models is efficient only under restrictive conditions. Moreover, firms always hire the most productive worker in the job auction model, which is not always true in the bargaining models. Blanchard and Diamond (1994) find that firms may hire less productive workers in preference to more productive ones in order to hold down the latter's wage demand.

Julien et al. (2000) also present a competing-auction theory of the labor market, but the sequence of events and the structure of auction are quite different from those in Shimer (1999). First, each candidate announces a reserve wage to induce offers from employers (thus essentially applying to all firms). Employers then decide which candidates to approach. Finally candidates auction their labor services to the highest bidder. The auction mechanism generates equilibrium wage dispersion among homogeneous workers and constrained-efficient entry of vacancies in large economies.

Job auctions yield the efficient market outcome. Kultti (1999) shows the equivalence of posted prices and auctions in large markets despite that his model is not dedicated to the labor market. Julien et al. $(2000,2005)$ and Shimer (1999) prove the efficiency of second-price and first-price auctions, respectively. Each firm's productivity is public information in all these studies.

In job auctions literature, Shimer (1999), Kultti (1999), and Julien et al. (2000) consider models with homogeneous firms. Julien et al. (2005) study small markets with heterogeneous firms, but they focus on the condition under which a mixed-strategy equilibrium exists and the efficiency of ex post bidding of wages. Our study contributes to the literature by introducing heterogeneous employers in the framework of Shimer (1999) and examines the interaction between different types of firms and job seekers. In a model setup with two-sided heterogeneity, the unique steady-state equilibrium is determined. The most engrossing result is that in equilibrium there is separation among the H-type job seekers, i.e., those with high productivity. The most capable ones separate themselves from other job applicants by applying only to the H-type (demanding) positions. The reasonably capable (but not top) candidates pool with the low-productivity workers in the job market at L-type vacancies. The condition of such separation is defined.

The remainder of this paper proceeds as following. Section 2 outlines the model, solves the equilibrium, and discusses the implications of the results. Section 3 connects the finding of the model to the general competitive auction theory in Peters (1997). Section 4 concludes.

\subsection{An asymmetric job auction model}

\subsection{Setup}

The basic setup in this paper is similar to Shimer (1999) but with key difference. In Shimer's original model, all the firms in the economy are identical, while only workers are different in their productivity. In this paper we explore the subject under two-sided heterogeneity. Firms are divided into two groups: one group is called hightech firms (H-type), the other is called routine firms (L-type). High-tech firms recruit workers with high productivity, while routine firms offer jobs that can be done by any worker.

The model setup is in a discrete time, infinite horizon context. During each period, unemployed workers randomly arrive at vacant jobs. Each employer observes workers' productivity and wage demand, and then hires at most one applicant. The employed worker starts working the next period.

There are continua of risk-neutral workers and firms. All discount the future with a common factor $\theta$. Normalize the measure of workers to 1 . Workers are distinguished by their productivity $x$ with cumulative distribution function $G(x)$ and density function $g(x)$.

The measure of firms is denoted by $M$. Assume that a fraction $\lambda$ of the firms are high-tech firms, so the total hightech jobs are of measure $\lambda M$. The other $(1-\lambda) M$ firms offer routine jobs. The productivity of a high-tech job is $y_{1}=p(x)$ for $x \in(\alpha, 1]$, and $y_{1}=0$ for $x \leq \alpha$. A worker whose productivity is below the threshold level $\alpha$ cannot create any positive output for high-tech firms. 
Denote workers with productivity $x \in(\alpha, 1]$ as H-type workers, those with $x \leq \alpha$ as L-type workers. The productivity of a routine job is $y_{2}=q(x)$ for $x \in[0,1]$, i.e., any worker can perform a routine job.

Assume that there is diminishing marginal product at each type of jobs. For workers who are capable of doing both types of jobs, the output from the match with H-type jobs grows faster in worker's type $x$ than that from a match with L-type jobs. These assumptions are characterized by $p^{\prime}(x)>0, p^{\prime \prime}(x) \leq 0, q^{\prime}(x)>0, q^{\prime \prime}(x) \leq 0$ and $p^{\prime}(x)>q^{\prime}(x)$ for all $x \in(\alpha, 1]$. To simplify our analysis, we use special functional forms satisfying the above conditions. From now on, let's assume $y_{1}=A x$ for $x \in(\alpha, 1]$ where $A>1$ and $y_{2}=x$ for $x \in[0,1] .^{2}$

Each unemployed worker applies for one vacant job randomly. Suppose that through cheap talk ${ }^{3}$ or some common knowledge, workers can distinguish high-tech job openings from routine ones. So by 'randomly,' we mean randomly arriving at one of the job openings of the desired type. This assumption further distinguishes our model from the model in Shimer (1999) where unemployed workers search purely randomly, and associates our model with directed search models. ${ }^{4}$ Clearly, an L-type worker will never apply for an H-type job; an H-type worker may apply for either type of job openings depending on the relative values to him. Since applications are independent of history, some vacancies get many applications, while others get none. This is the well-known coordination friction in the labor market.

Matches at high-tech firms are destroyed with probability $\delta_{1}$, and matches at routine jobs are destroyed with probability $\delta_{2}$. Assume that both job destruction rates are exogenous and $\delta_{2}>\delta_{1}$. When a match is destroyed the firm and the worker will return to the search market next period.

\subsubsection{Firms}

To construct the steady-state equilibrium, we first start with firms' value functions. Let $J_{1}^{F}$ be the expected value of a high-tech firm with a filled job, $J_{1}^{V}$ be that of a high-tech vacancy; let $J_{2}^{F}$ be the expected value of a filled routine job, $J_{2}^{V}$ be that of a vacant routine job. When an applicant bids $\Pi$ (with the surplus going to the potential employer) at each type of firms, the value functions are respectively,

$$
\begin{aligned}
& J_{1}^{F}(\Pi)=\Pi+\theta \delta_{1} \cdot J_{1}^{V}+\theta\left(1-\delta_{1}\right) \cdot J_{1}^{F}(\Pi) \\
& J_{2}^{F}(\Pi)=\Pi+\theta \delta_{2} \cdot J_{2}^{V}+\theta\left(1-\delta_{2}\right) \cdot J_{2}^{F}(\Pi)
\end{aligned}
$$

Each firm's expected value is the sum of this period's profit, and the discounted value of the future value functions depending on whether the job match is destructed at the end of the current period. Rearranging the above equations, we get

$$
\begin{aligned}
& J_{1}^{F}(\Pi)=\frac{\Pi+\theta \delta_{1} \cdot J_{1}^{V}}{1-\theta\left(1-\delta_{1}\right)} \\
& J_{2}^{F}(\Pi)=\frac{\Pi+\theta \delta_{2} \cdot J_{2}^{V}}{1-\theta\left(1-\delta_{2}\right)}
\end{aligned}
$$

A high-tech firm will hire a high bid of $\Pi$ if $J_{1}^{F}(\Pi)-J_{1}^{V}=\frac{\Pi-(1-\theta) J_{1}^{V}}{1-\theta\left(1-\delta_{1}\right)} \geq 0$.

Define $j_{1}^{V}=(1-\theta) J_{1}^{V}$. So a high bid of $\Pi$ will be accepted if $\Pi \geq j_{1}^{V}$.

Similarly, a routine job opening will hire a high bid of $\Pi$ if $\Pi \geq j_{2}^{V}=(1-\theta) J_{2}^{V}$. Note that $j_{1}^{V}$ and $j_{2}^{V}$ are the reserve prices of the two types of jobs at auction respectively.

\footnotetext{
2 This is a Cobb-Douglas production function with capital input normalized to 1 in both types of jobs.

${ }^{3}$ Kim and Kircher (2011) show that the same efficient outcomes can be achieved when firms make cheap talk communications rather than making firm commitment. Job seekers can gain sufficient valuable information through cheap talks.

${ }^{4}$ As the name suggests, directed search means that unemployed workers direct their search efforts towards particular type of job vacancies.
} 


\section{Hiring probability}

The actual number of applications is a random variable following Poisson distribution. Given the firms' value functions, the hiring probability of a worker bidding $\Pi$ is given by either $P_{1}(\Pi)$ or $P_{2}(\Pi)$ as

$$
\begin{aligned}
& P_{1}(\Pi)= \begin{cases}\exp \left(-\frac{H_{1}(\Pi)}{V_{1}}\right) & \text { if } \Pi \geq j_{1}^{V} \\
0 & \text { otherwise }\end{cases} \\
& P_{2}(\Pi)= \begin{cases}\exp \left(-\frac{H_{2}(\Pi)}{V_{2}}\right) & \text { if } \Pi \geq j_{2}^{V} \\
0 & \text { otherwise }\end{cases}
\end{aligned}
$$

Where $H_{1}(\Pi)$ is the total number of applications at $\mathrm{H}$-type vacancies that bid at least $\Pi ; H_{2}(\Pi)$ is the number of applications at L-type vacancies that bid at least $\Pi$. $V_{1}$ and $V_{2}$ are the number of H-type and L-type vacancies respectively.

It is important to note that job auctions are held anonymously, so the hiring probability of a worker bidding $\Pi$ is the same for all at each type of vacancies.

\subsubsection{Workers}

We now look at workers' Bellman equations. In what follows, workers with productivity greater than $\alpha$ are denoted with subscript $\mathrm{H}$. Those with productivity less than $\alpha$ is denoted with subscript $\mathrm{L}$.

\section{Employed workers}

An H-type worker being employed at an H-type job has value function $J_{H 1}^{E}$ where

$$
J_{H 1}^{E}(x, \Pi)=A x-\Pi+\theta \delta_{1} J_{H}^{U}(x)+\theta\left(1-\delta_{1}\right) J_{H 1}^{E}(x, \Pi)
$$

An H-type worker being employed at an L-type job has value function $J_{H 2}^{E}$ where

$J_{H 2}^{E}(x, \Pi)=x-\Pi+\theta \delta_{2} J_{H}^{U}(x)+\theta\left(1-\delta_{2}\right) J_{H 2}^{E}(x, \Pi)$

An L-type worker being employed at an L-type job has value function $J_{L}^{E}$, where

$$
J_{L}^{E}(x, \Pi)=x-\Pi+\theta \delta_{2} J_{L}^{U}(x)+\theta\left(1-\delta_{2}\right) J_{L}^{E}(x, \Pi)
$$

Unemployed workers

An L-type worker that is unemployed has the value function of

$$
J_{L}^{U}(x)=\theta \max _{\Pi} P_{2}(\Pi) \cdot\left(1-\delta_{2}\right) \cdot J_{L}^{E}(x, \Pi)+\left[1-P_{2}(\Pi) \cdot\left(1-\delta_{2}\right)\right] \cdot J_{L}^{U}
$$

That is, he will choose an optimal bid to maximize the expected value of applying for an L-type job vacancy. An H-type worker that is currently unemployed has the value of

$$
\begin{aligned}
J_{H}^{U}(x)=\theta \max \left\{\max _{\Pi} P_{1}(\Pi) \cdot\left(1-\delta_{1}\right) J_{H 1}^{E}(x, \Pi)+\left[1-P_{1}(\Pi) \cdot\left(1-\delta_{1}\right)\right] J_{H}^{U},\right. \\
\left.\max _{\Pi} P_{2}(\Pi) \cdot\left(1-\delta_{2}\right) J_{H 2}^{E}(x, \Pi)+\left[1-P_{2}(\Pi) \cdot\left(1-\delta_{2}\right)\right] J_{H}^{U}\right\}
\end{aligned}
$$

That is, he will compare the expected values of applying to an L-type vacancy and an H-type vacancy, and apply to the type that yields a higher expected value.

Define $j_{L}^{U}(x)=(1-\theta) J_{L}^{U}(x)$. From the expressions of $J_{L}^{U}(x)$ and $J_{L}^{E}(x, \Pi)$, we can get

$$
j_{L}^{U}(x)=\frac{\theta\left(1-\delta_{2}\right)}{1-\theta\left(1-\delta_{2}\right)} \cdot \max _{\Pi} P_{2}(\Pi)\left[x-\Pi-j_{L}^{U}(x)\right]
$$

Define $j_{H}^{U}(x)=(1-\theta) J_{H}^{U}(x)$. From the expressions of $J_{H}^{U}(x), J_{H 1}^{E}(x, \Pi)$ and $J_{H 2}^{E}(x, \Pi)$, we have the following expression:

$j_{H}^{U}(x)=\max \left\{\frac{\theta\left(1-\delta_{1}\right)}{1-\theta\left(1-\delta_{1}\right)} \max _{\Pi} P_{1}(\Pi)\left[A x-\Pi-j_{H}^{U}(x)\right], \frac{\theta\left(1-\delta_{2}\right)}{1-\theta\left(1-\delta_{2}\right)} \max _{\Pi} P_{2}(\Pi)\left[x-\Pi-j_{H}^{U}(x)\right]\right\}$ 


\subsection{Steady-state equilibrium}

As in Shimer (1999), the steady-state equilibrium in this dynamic model is characterized by:

1. Workers make wage demands to maximize their expected wealth;

2. Firms hire the applicant who yields the highest profit $\Pi$ or no one if that is more profitable;

3. All distributions and prices are time-invariant.

Let $\Pi_{1}(x)$ and $\Pi_{2}(x)$ be the optimal solutions of the two maximization problems in (11). We substitute $K\left(\Pi_{1}(x)\right)$ for the first term in the curly brackets, $Z\left(\Pi_{2}(x)\right)$ for the second term. Then we can express the above Bellman equations as

$$
\begin{aligned}
& \text { For } x \in[0, \alpha], j^{U}(x)=Z\left(\Pi_{2}(x)\right) . \\
& \text { For } x \in(\alpha, 1], j^{U}(x)=\max \left\{K\left(\Pi_{1}(x)\right), Z\left(\Pi_{2}(x)\right)\right\} .
\end{aligned}
$$

It is reasonable at the current stage to form the conjecture that, after some cutoff value $\bar{x} \in(\alpha, 1)$, $K\left(\Pi_{1}(x)\right)>Z\left(\Pi_{2}(x)\right)$, i.e., the expected payoff from applying at an H-type vacancy is strictly greater than that from applying at an L-type vacancy. Hence, workers with productivity less than $\bar{x}$ will apply for L-type jobs, and workers with productivity greater than $\bar{x}$ apply for H-type jobs. Even though $\mathrm{H}$-type workers are capable of doing both jobs, they diverge into two groups. The most capable ones separate themselves from other job applicants by applying only to the H-type (demanding) positions. The reasonably capable (but not top) candidates pool with the low-productivity workers in the job market at L-type vacancies. In each group the value functions are continuous in workers' productivity.

The following result gives the sufficient conditions under which the cutoff value $\bar{x}$ exists.

Proposition 1. There exists a cutoff value $\bar{x}$ between $\alpha$ and one, if the hiring probability is weakly higher at the $H$ type than at the L-type vacancies under optimal bidding strategies, and $j^{U^{\prime}}(x) \leq 1$. Workers whose productivity is higher than $\bar{x}$ will only apply to H-type job vacancies.

Proof: see Appendix.

The condition that the hiring probability for a highly productive worker is higher at an H-type job is consistent with previous research in search and matching models. Shimer (2005) studies the assignment of heterogeneous workers to heterogeneous jobs. He finds that a more productive worker is more likely to match with a highproductivity firm than with a low-productivity firm, compared to a less productive worker. There exists a positive correlation between the worker's type and the employer's type.

Corollary 1 follows indicating that the cutoff value $\bar{x}$ is between $\alpha$ and one.

Corollary 1. For workers with productivity $\bar{x}$ and higher, the expected wage in an H-type job offer is strictly higher than that in an L-type job offer.

Proof: see Appendix.

What if $K\left(\Pi_{1}(x)\right)-Z\left(\Pi_{2}(x)\right)$ is not a monotonic function of $x$ and the cutoff value does not exist? Then all Htype workers will apply to either type of job openings, while L-type workers will still apply to routine jobs. This situation reverses the setup in Peters (2005), where applicants only apply to job openings of quality equal to or higher than their own.

Given that a cutoff value exists in the distribution of $x$, we can then apply the methods in Shimer (1999) to construct the steady-state equilibrium.

Proposition 2. The unique steady-state equilibrium is determined by $V_{1}, V_{2}, Q_{1}, Q_{2}, j_{2}^{V}$ and $\bar{x}$, where $V_{1}$ and $V_{2}$ are the number of job vacancies at each type of firms, $Q_{1}$ and $Q_{2}$ are the corresponding queue length, $j_{2}^{V}$ is the value of a vacant L-type job, and $\bar{x}$ is the cutoff value in labor productivity that divides the pool of applicants.

Proof: see Appendix. 


\subsection{Discussions and implication of results}

Job auction models, belonging to "competitive search" models, internalize the determination of the share of surplus, and endogenously generate incentives for efficient division of the matching surplus. Bargaining models, in contrast, yield efficient outcomes only when the Hosios condition holds, i.e., the worker's share of the surplus must be equal to the elasticity of the employer's contact rate with respect to queue length.

The model in this paper makes several predictions about the interaction among workers in a labor market where unemployment and job vacancies coexist. First, an increase in the cutoff value that separates the most productive workers from the rest of the unemployed will reduce the competition at the $\mathrm{H}$-type vacancies, which will result in lower bids and thus higher wage demands at $\mathrm{H}$-type jobs in equilibrium. Meanwhile, the pool of applicants at the L-type job vacancies becomes larger, creating more pressure on these job seekers to make higher bids and thus accept lower wages.

Second, the equilibrium bid depends on the queue length at a vacancy. In the efficient outcome of job auction models, a more productive applicant is always hired in preference to less productive ones, because the subsequent match will generate higher output for the firm. Therefore, it is the less productive applicants that make their bids more aggressively to increase the chance of winning the job auction.

Finally, when the unemployment rate of more productive workers rises, the expected value of applying at an $\mathrm{H}$ type job vacancy declines and L-type jobs become relatively more attractive. The queue length at L-type job vacancies will increase, and as a result, the unemployment rate of less productive workers will rise. This ripple effect originates from a few job sectors and gradually spreads over the entire labor market.

\subsection{Auction in a Frictional Labor Market}

In auction theories McAfee (1993) studies a dynamic model with many sellers and many buyers. Equilibrium is found where sellers hold identical auctions and buyers randomize over the sellers they visit. Auctions alter the distribution of buyer types by removing high value buyers more rapidly than low value buyers. Sellers in equilibrium post an efficient reserve price equal to the seller's value of the good, and an auction with an efficient reserve price is the optimal mechanism from the sellers' point of view.

Peters (1997) generalizes McAfee's results in two ways. First, McAfee assumes that sellers in the finite version of the model ignore the externalities that their deviations create when choosing among the mechanisms. This assumption is relaxed in Peters (1997). Second, McAfee assumes that sellers are identical, while Peters (1997) allows for cost asymmetry. The essential assumption in Peters' model is that the support of the distribution of seller valuations is contained in the support of the distribution of buyer valuations.

The central result of Peters (1997) is that there is an equilibrium when sellers compete in direct mechanisms where all sellers offer buyers second price sealed-bid auction with reservation prices equal to their costs. The result may have a Bertrand flavor at the first glance. However, sellers continue to earn positive profits in equilibrium from buyers who submit bids above their costs. In the limit game, no matter what mechanism is offered by a deviating seller, the induced distribution of reserve prices converges weakly to the same distribution. Furthermore, the deviating seller's payoff is bounded above by the payoff associated with holding an auction with reserve price equal to the seller's cost.

Peters' theory of competitive auctions can be applied to job markets. In job auctions such as our model, each firm holds an auction to recruit workers, which is essentially a mechanism of competitive auction. Two types of firms have distinctive costs, i.e., reserve prices at the auctions. Here firms with vacancy are the sellers. Job applicants are the buyers who bid in the auction on how much they can offer to the firm.

Applying Peters' theory to the context of our model, suppose that sellers' cost can take only one of two values, $j_{1}^{V}$ and $j_{2}^{V}, j_{1}^{V}>j_{2}^{V}$. A fraction $\lambda$ of all sellers, the high-tech firms, have the cost $j_{1}^{V}$. Then in the equilibrium distribution of auctions, the proportion $\lambda$ of all sellers will set reserve price $j_{1}^{V}$, and attract buyers whose evaluation exceeds the solution $y$ to the equation

$y=j_{1}^{V}-j_{2}^{V}+\frac{\int_{0}^{y} \exp \left[\frac{1}{M}\left[\frac{G(y)-G(s)}{1-\lambda}+1-G(y)\right]\right] d s}{\exp \left[\frac{1}{M}(1-G(y))\right]}$ 
where $M$ is the measure of firms, $G(\cdot)$ is the CDF of buyers' evaluation of the object. The other $1-\lambda$ sellers (regular firms) will set reserve price $j_{2}^{V}$, and attract all buyers whose evaluation exceeds $j_{2}^{V}$. Therefore, in equilibrium workers with very high productivity only apply to H-type job vacancies, and other job seekers apply to the L-type vacancies.

\subsection{Conclusion}

In this paper we investigate a labor market with an auction framework. Workers with heterogeneous productivity apply to two types of job vacancies, by bidding the profits that they can offer the firm. In the steady state equilibrium, the most capable workers separate themselves from others by only bidding at jobs requiring high skills, while applicants in the middle of the distribution of productivity will pool with the low-productivity workers and apply for jobs requiring low skills.

As policy implications, the results of this paper suggest that high-end job market sectors would impact the entire labor market. When the knowledge-based and innovation-driven sectors are well established and active in an economy, highly-qualified and well-educated workers will find appropriate positions that fit their skill sets. Such match would also promote employment in other sectors of the labor market. On the other hand, if the high-end labor market encounters challenges, the ripple effect will spread over the entire market, causing widespread rising unemployment and waste of human capital. This implication is consistent with the popular economic strategy that promotes the development of knowledge-based economic sectors that can export positive effect to other sectors.

Another implication of the results in this paper is that governments should coordinate their policies and strategies on industry development and education. Advanced education (especially at post graduate level) often produces productive workers for specialized economic sectors. These workers can make significant contributions to the economy when healthy economic sectors exist that match their skill sets. Mismatch between governments' strategies on eduction and industry development would not only waste human capital and financial resources but also cause structural challenges in labor market.

There are a couple of extensions that may be worthwhile to explore. It would be interesting to add 'on the job search' to this job auction model so that the job destruction rate is endogenous, which will capture more factual observations on the job market.

There is no explicit role for capital in our model, which separates our paper from some literature. For example, Montgomery (1991) finds that the probability of filling a vacancy is an increasing function of the wage offered, therefore in equilibrium, firms that find vacancies more costly (such as having higher capital-labor ratio or having more market power) will offer higher wages. In a model where firms need to invest in capital before posting a vacancy, Jansen (2010) shows that the equilibrium is efficient with directed search if job applicants can condition their application decision on firm's investment level; however, with random search there is underinvestment in capital (or hold-up problem). The idea that it is more costly to hold an H-type vacancy, in our model, is captured by a higher expected value function for the H-type vacancy, due to higher output if match is formed, and the lower destruction rate for $\mathrm{H}$-type jobs. As future research it would be of interest to explore the effect of including capital in the production function.

\section{Appendix}

Proof of Proposition 1.

Denote $R(x)=K\left(\Pi_{1}(x)\right)-Z\left(\Pi_{2}(x)\right)$. Applying Envelope Theorem,

$R^{\prime}(x)=\frac{\theta\left(1-\delta_{1}\right)}{1-\theta\left(1-\delta_{1}\right)} P_{1}\left(\Pi_{1}(x)\right) \cdot\left[A-j^{U^{\prime}}(x)\right]-\frac{\theta\left(1-\delta_{2}\right)}{1-\theta\left(1-\delta_{2}\right)} P_{2}\left(\Pi_{2}(x)\right) \cdot\left[1-j^{U^{\prime}}(x)\right]$

Under the assumption that $A>1$,

$R^{\prime}(x)>\left[1-j^{U^{\prime}}(x)\right] \cdot\left[\frac{\theta\left(1-\delta_{1}\right)}{1-\theta\left(1-\delta_{1}\right)} P_{1}\left(\Pi_{1}\right)-\frac{\theta\left(1-\delta_{2}\right)}{1-\theta\left(1-\delta_{2}\right)} P_{2}\left(\Pi_{2}\right)\right]$ 
We know that $\delta_{1}<\delta_{2}$, therefore $\frac{\theta\left(1-\delta_{1}\right)}{1-\theta\left(1-\delta_{1}\right)}>\frac{\theta\left(1-\delta_{2}\right)}{1-\theta\left(1-\delta_{2}\right)}$. In order for $R^{\prime}(x)>0$, it is sufficient but not necessary to satisfy the conditions $j^{U^{\prime}}(x) \leq 1$ and $P_{1}\left(\Pi_{1}(x)\right) \geq P_{2}\left(\Pi_{2}(x)\right)$ for $x \in(\alpha, 1]$. Such conditions being met, $R(x)$ is monotonically increasing in $x$ for $x \in(\alpha, 1]$. QED

Proof of Corollary 1.

$$
\begin{aligned}
& \text { At } \bar{x}, R(\bar{x})=0 \text { i.e. } K\left(\Pi_{1}(\bar{x})\right)=Z\left(\Pi_{2}(\bar{x})\right) \text {, or } \\
& \frac{\theta\left(1-\delta_{1}\right)}{1-\theta\left(1-\delta_{1}\right)} P_{1}\left(\Pi_{1}\right)\left[A \bar{x}-\Pi_{1}(x)-j^{U}(\bar{x})\right]=\frac{\theta\left(1-\delta_{2}\right)}{1-\theta\left(1-\delta_{2}\right)} P_{2}\left(\Pi_{2}\right)\left[\bar{x}-\Pi_{2}(\bar{x})-j^{U}(\bar{x})\right] \\
& \text { Since } \frac{\theta\left(1-\delta_{1}\right)}{1-\theta\left(1-\delta_{1}\right)}>\frac{\theta\left(1-\delta_{2}\right)}{1-\theta\left(1-\delta_{2}\right)} \text {, and } P_{1}\left(\Pi_{1}(x)\right) \geq P_{2}\left(\Pi_{2}(x)\right) \text { for } x \in(\alpha, 1] \text {, the cutoff value }
\end{aligned}
$$
$\bar{x} \in(\alpha, 1)$ requires $A \bar{x}-\Pi_{1}(x)<\bar{x}-\Pi_{2}(x)$, which is obviously $W_{1}(\bar{x})<W_{2}(\bar{x})$. QED

\section{Proof of Proposition 2.}

Recall that $P_{2}(\Pi(x))=\exp \left(-Q_{2}(x)\right)$, where $Q_{2}(x)=\frac{1}{V_{2}} \cdot \int_{x}^{\bar{x}} u_{L}(y) d y$ is the queue length or the expected number of applicants at an L-type job opening. For $j_{2}^{V}<x<\bar{x}$, the total number of successful matches equals the total number of destroyed jobs at the steady-state equilibrium, i.e.

$$
\left(1-\delta_{2}\right) \exp \left(-Q_{2}(x)\right) \cdot u_{L}(x)=\delta_{2}\left(g(x)-u_{L}(x)\right)
$$

Since $Q_{2}^{\prime}(x)=-u_{L}(x) / V_{2}$, equation (A.1) can be rewritten as a first-order differential equation of $x$,

$$
\frac{d}{d x}\left[V_{2}\left(1-\delta_{2}\right) \exp \left(-Q_{2}(x)\right)-\delta_{2} V_{2} Q_{2}(x)\right]=\delta_{2} g(x)
$$

Solving (A.2), we get

$$
V_{2}\left(1-\delta_{2}\right) \exp \left(-Q_{2}(x)\right)-\delta_{2} V_{2} Q_{2}(x)=\delta_{2} G(x)+k
$$

At $x=\bar{x}, Q_{2}(x)=0$. Use this terminal condition to find

$$
k=V_{2}\left(1-\delta_{2}\right)-\delta_{2} G(\bar{x})
$$

Substitute $k$ back into (A.3),

$$
\left(1-\delta_{2}\right) V_{2}\left[1-\exp \left(-Q_{2}(x)\right)\right]=\delta_{2}\left[G(\bar{x})-G(x)-V_{2} Q_{2}(x)\right]
$$

An L-type job vacancy gets a worker with probability $1-\left(1-1 / V_{2}\right)^{H_{2}}$. By taking the limit of this expression as $V_{2}$ and $H_{2}$ go to infinity while $Q_{2}=H_{2} / V_{2}$ remains fixed, we find that in a large market the fraction $1-\exp \left(-Q_{2}\right)$ of L-type vacancies get a worker.

In steady state, the flow into the L-type firms equals the job destruction at those firms.

Similarly, for $\bar{x}<x \leq 1$,

$\left(1-\delta_{1}\right) V_{1}\left[1-\exp \left(-Q_{1}(x)\right)\right]=\delta_{1}\left[1-G(x)-V_{1} Q_{1}(x)\right]$

Therefore, the total employment at L-type firms (or the number of filled L-type jobs) is given by

$$
\int_{j_{2}^{V}}^{\bar{x}}\left(g(x)-u_{L}(x)\right) d x=\int_{j_{2}^{V}}^{\bar{x}} \frac{\left(1-\delta_{2}\right) \exp \left(-Q_{2}(x)\right)}{\delta_{2}+\left(1-\delta_{2}\right) \exp \left(-Q_{2}(x)\right)} g(x) d x
$$

Total employment at H-type firms is

$$
\int_{\bar{x}}^{1}\left(g(x)-u_{H}(x)\right) d x=\int_{\bar{x}}^{1} \frac{\left(1-\delta_{1}\right) \exp \left(-Q_{1}(x)\right)}{\delta_{1}+\left(1-\delta_{1}\right) \exp \left(-Q_{1}(x)\right)} g(x) d x
$$

We then express the value of unemployment in terms of queue length and reserve prices. Recall that

$$
j_{L}^{U}(x)=\frac{\theta\left(1-\delta_{2}\right)}{1-\theta\left(1-\delta_{2}\right)} \cdot \max _{\Pi} P_{2}(\Pi)\left[x-\Pi-j_{L}^{U}(x)\right]
$$

By Envelope Theorem, 


$$
j_{L}^{U^{\prime}}(x)=\frac{\theta\left(1-\delta_{2}\right)}{1-\theta\left(1-\delta_{2}\right)} \cdot P_{2}\left(\Pi_{2}(x)\right)\left[1-j_{L}^{U^{\prime}}(x)\right]
$$

Hence, for $j_{2}^{V}<x<\bar{x}$,

$$
j_{L}^{U^{\prime}}(x)=\frac{\theta\left(1-\delta_{2}\right) \cdot \exp \left(-Q_{2}(x)\right)}{1-\theta\left(1-\delta_{2}\right)\left[1-\exp \left(-Q_{2}(x)\right)\right]}
$$

Integrate the above equation from $j_{2}^{V}$ to $x$, we get

$$
j_{L}^{U}(x)=\int_{j_{2}^{V}}^{x} \frac{\theta\left(1-\delta_{2}\right) \cdot \exp \left(-Q_{2}(y)\right)}{1-\theta\left(1-\delta_{2}\right)\left[1-\exp \left(-Q_{2}(y)\right)\right]} d y
$$

Similarly, for $\bar{x}<x<1$,

$$
j_{H}^{U}(x)=\int_{\bar{x}}^{x} \frac{A \theta\left(1-\delta_{1}\right) \cdot \exp \left(-Q_{1}(y)\right)}{1-\theta\left(1-\delta_{1}\right)\left[1-\exp \left(-Q_{1}(y)\right)\right]} d y
$$

To close the model, we finally calculate the value of a vacant L-type job

$$
j_{2}^{V}=\theta\left(1-\delta_{2}\right) \int_{j_{2}^{V}}^{\bar{x}}\left(J_{2}^{F}\left(\Pi_{2}(x)\right)-J_{2}^{V}\right) \exp \left(-Q_{2}(x)\right)\left(-Q_{2}{ }^{\prime}(x)\right) d x
$$

where $J_{2}^{F}\left(\Pi_{2}(x)\right)-J_{2}^{V}$ is the net value gained from a filled vacancy, $\exp \left(-Q_{2}(x)\right)\left(-Q_{2}^{\prime}(x)\right)$ is the density of the most productive applicant. Substitute in $J_{2}^{F}$ and $J_{2}^{V}$,

$$
j_{2}^{V}=\theta\left(1-\delta_{2}\right) \int_{j_{2}^{V}}^{\bar{x}} \frac{1-\left(1+Q_{2}(x)\right) \exp \left(-Q_{2}(x)\right)}{1-\theta\left(1-\delta_{2}\right)\left(1-\exp \left(-Q_{2}(x)\right)\right)} d x
$$

In the unique steady-state equilibrium, the number of job vacancies $V_{1}$ and $V_{2}$, the respective queue lengths $Q_{1}$ and $Q_{2}$, the value or reserve price of a vacant L-type job $j_{2}^{V}$, and the cutoff value in the distribution of labor productivity, $\bar{x}$, are jointly determined by equations (A.4), (A.5), (A.6), (A.7), (A.9), (A.10), and (A.12). QED

\section{References}

Acemoglu D., Shimer R., (1999a). Efficient unemployment insurance. Journal of Political Economy, 107(5): 893 928. http://dx.doi.org/10.1086/250084

Acemoglu D., Shimer R., (1999b). Holdups and efficiency with search frictions. International Economic Review, 40(4): 827-849. http://dx.doi.org/10.1111/1468-2354.00043

Blanchard O., Diamond P., (1994). Ranking, unemployment duration and wages. Review of Economics Studies, 61(3): 417-434. http://dx.doi.org/10.2307/2297897

Burdett K., Mortensen D., (1998). Wage differentials, employer size, and unemployment. International Economic Review, 39(2): 257-273. http://dx.doi.org/10.2307/2527292

Eeckhout J., Kircher P., (2010). Sorting and decentralized price competition, Econometrica, 78(2): 539-574. http://dx.doi.org/10.3982/ECTA7953

Hosios A.J., (1990). On the efficiency of matching and related models of search and unemployment. The Review of Economic Studies, 57(2): 279-298. http://dx.doi.org/10.2307/2297382

Jansen M., (2010). Job Auctions and hold-ups. Labour Economics, 17(3): 608-619. http://dx.doi.org/10.1016/j.labeco.2009.05.006

Julien B., Kennes J., King I., (2000). Bidding for labor. Review of Economic Dynamics, 3(4): 619-649. http://dx.doi.org/10.1006/redy.1999.0089

Julien B., Kennes J., King I., (2005). Ex post bidding and efficient coordination unemployment. Canadian Journal of Economics, 38(1): 174-193. http://dx.doi.org/10.1111/j.0008-4085.2005.00274.x

Kim K., Kircher P., (2011). A theory of decentralized trade with communication. Working Paper, University of Iowa.

Kultti K., (1999). Equivalence of auctions and posted prices. Games and Economic Behavior, 27(1): 106-113. http://dx.doi.org/10.1006/game.1998.0658

McAfee R.P., (1993). Mechanism design by competing sellers. Econometrica, 61(6): 1281-1312. http://dx.doi.org/10.2307/2951643 
Moen E.R., (1997). Competitive search equilibrium. Journal of Political Economy, 105(2): 385-411. http://dx.doi.org/10.1086/262077

Montgomery J., (1991). Equilibrium wage dispersion and inter-industry wage differentials. Quarterly Journal of Economics, 106(1): 163-179. http://dx.doi.org/10.2307/2937911

Mortensen D.T., Wright R., (2002). Competitive pricing and efficiency in search equilibrium. International Economic Review, 43(1): 1-20. http://dx.doi.org/10.1111/1468-2354.t01-1-00001

Peters M., (1997). A competitive distribution of auctions. Review of Economic Studies, 64(1): 97-123. http://dx.doi.org/10.2307/2971742

Peters M., (2005). Unobservable heterogeneity in directed search. Working Paper, University of British Columbia. Pissarides C., (1990). Equilibrium Unemployment Theory. Massachusetts: MIT Press.

Rogerson R., Shimer R., Wright R., (2005). Search-theoretic models of the labor market - a survey. Journal of Economic Literature, 43(4): 959-988. http://dx.doi.org/10.1257/002205105775362014

Shi S., (2001). Frictional assignment I: efficiency. Journal of Economic Theory, 98(2): 232-260. http://dx.doi.org/10.1006/jeth.2000.2713

Shimer R., (1999). Job auctions. Working Paper, Princeton University.

Shimer R., (2005). The assignment of workers to jobs in an economy with coordination frictions. Journal of Political Economy, 113(5): 996-1025. http://dx.doi.org/10.1086/444551 